\title{
EDITORIAL
}

\section{Interdisciplinary Quaternary Research and Environmental History}

Sir Archibald Geike's famous statement that "the present is the key to the past," which so succinctly summarizes the philosophy of Hutton and his successors, is true if allowance is made for variation in the intensity of geologic processes with time. This uniformitarian philosophy has made possible the unraveling of a good deal of environmental history, espccially with respect to the Quaternary Period-the most recent period of earth history leading from the past to the present and encompassing our contemporary natural environment. As such the Quaternary Period is the one with the greatest wealth of data concerning environmental changes.

Some of the changes have been of worldwide significance. Quaternary climatic fluctuations repeatedly led to extensive advances and retreats of glaciers in now temperate latitudes, to formation and disappearance of vast lakes, to rises and falls of sea level by hundreds of feet, and to large variations in the distribution of plants and animals. Study of the Quaternary is primarily an examination of our natural surroundings from an historical viewpoint, since, processes operating during this period were responsible for much of our present physical and biological environment and for the emergence of man. Although emphasis is on history, the present is common ground for the Quaternary researcher and for colleagues concerned with environmental processes and changes occurring today.

The study of the Quaternary is a notable example of interdisciplinary co- operation. Thus, anthropology and archaeology are concerned with environmental history in tracing the rise of man (and perhaps his eventual fall). Astronomy has contributed to theories of climatic change, and the atmospheric sciences are particularly interested in discovering the causes. The reason for the repeated Quaternary glaciations is unknown, and this lack of knowledgc inhibits forecasts regarding future climatic trends. Botany, forestry, and zoology draw on Quaternary studies to explain the present distribution of many plants and animals and to forecast the effect of ecological disturbances. Palynology-the study of fossil pollen and their stratigraphic sequence-provides a powerful tool for reconstructing vegetational successions as related to climate and ecology. Pedology includes soil genesis and the history of soil development during the Quaternary Period. Many engineering problems require a knowledge of past events, such as earth movements of various kinds that might indicate unstable sites and thereby affect construction projects. Environmental geology is becoming an important field requiring detailed quantitative information regarding hydrologic conditions, permafrost, and processes of erosion and sedimentation in various environments, as well as knowledge of other processes and events such as volcanism and earthquakes. These matters can affect the daily lives of millions of people and are critical to environmental planning, a field that is central to much geographic rcsearch. Oceanography has its own realm 
of environmental problems, many of which closely interact with terrestrial problems and have common causes. The congresses of the International Quaternary Union are based on these interdisciplinary interests in Quaternary environments, as are the growing number of Quaternary associations in many parts of the world, the latest being the American Quaternary Association established in 1969. Quaternary research, with its emphasis on the canses and interactions that have shaped our surroundings and are continuing to change them, is playing an increasingIy critical role by providing insight into the nature and variable effects of environmental processes with time. In this context. and without circular reasoning. we can also in- vert Sir Archibald Geike's statement by saying that the past is the key to the present. Quaternary Rescarch-An Interdisciplinary Journal will focus on Quaternary research as outlined in the preceding paragraphs. Editorial policy will therefore emphasize interdisciplinary relevance as well as scientific quality when articles are being considered for publication. Interdisciplinary relevance means that an article should be of reasonably wide interest and must have clear significance for workers in two or more disciplines. Articles written from the viewpoint of a single discipline are included under this definition, provided the topic is of interdisciplinary interest.

A. L. WASHBURN 